\title{
EXTRAÇÃO DE COLORANTE NATURAL INTRACELULAR DE Talaromyces amestolkiae UTILIZANDO SONICADOR E LÍQUIDO IÔNICO COMO AGENTE EXTRATOR
}

\author{
P. R. HIRAI ${ }^{1}$, M. F. S. TEIXEIRA ${ }^{2}$, J. F. B. PEREIRA ${ }^{1}$, V. C. SANTOS-EBINUMA ${ }^{1}$. \\ ${ }^{1}$ UNESP - Universidade Estadual Paulista, Faculdade de Ciências Farmacêuticas, \\ Departamento de Bioprocessos e Biotecnologia. \\ ${ }^{2}$ Universidade Federal do Amazonas. \\ E-mail para contato: patirie2002@ hotmail.com
}

\begin{abstract}
RESUMO - Devido à crescente tendência em substituir colorantes sintéticos por naturais, o objetivo deste trabalho foi avaliar diferentes metodologias utilizando sonicador como rompedor celular e o líquido iônico (LI) cloreto de 1-butil-3methilimidazolio $\left[\mathrm{C}_{4 \mathrm{mim}}\right] \mathrm{Cl}$ como agente extrator. Primeiramente, avaliou-se a extração com sonicador ( relação massa:volume LI igual a $1: 3 \mathrm{~m} / \mathrm{v}$ e 5 ciclos de 5 min em sonicador e 1 min em banho de gelo) seguido por manutenção em banho rotativo nos tempos de 0,30 e $90 \mathrm{~min}$, a fim de avaliar o parâmetro tempo no processo de extração dos colorantes naturais. Em seguida, realizou-se ensaio com 10 ciclos em sonicador para posterior comparação. Por fim, realizou-se o terceiro ensaio nas mesmas proporções de biomassa e LI em homogeneizador por $3 \mathrm{~h}$. Em todos os ensaios os tubos foram centrifugados e o sobrenadante retirado para posteriores analises. A partir dos resultados obtidos, fixou-se 30 min o tempo em banho rotativo como metodologia padrão, pois, o maior tempo de contato do LI com a biomassa não acarretou em eficiência de extração superior. Além disso, foi possível observar que a melhor metodologia para extrair os colorantes naturais intracelulares foi empregando sonicador, uma vez que o aparelho proporciona maior poder de quebra das ligações químicas presentes na parede celular de Talaromyces amestolkiae. Desta maneira, o processo de sonicação com LI da família dos Imidazólios como agente extrator pode ser empregado para a obtenção de colorantes naturais intracelulares.
\end{abstract}

\section{INTRODUÇÃO}

Atualmente, devido ao aumento da procura de produtos naturais, corantes sintéticos são amplamente substituídos por corantes naturais, uma vez que os sintéticos podem ser tóxicos e apresentar ação mutagênica e carcinogênica (Santos-Ebinuma, 2013). Os colorantes naturais são utilizados para melhorar a aparência dos produtos farmacêuticos, alimentícios e cosméticos, a fim de aumentar a preferência e aceitabilidade dos consumidores (Torres et al, 2016). Estes podem ser derivados de plantas, insetos e microorganismos.

A produção por fungos filamentosos pode ser destacada e as espécies de Talaromyces são

consideradas potenciais produtores de corantes naturais. Entre as espécies de 
Talaromyces, T. amestolkiae pode produzir corantes em meio líquido (Santos-Ebinuma, 2014). Essa espécie de fungo é promissora, pois é capaz de crescer em meio de cultura de baixo custo e produzir grandes quantidades do produto de interesse (Souza, 2015).

Os fungos filamentosos são muito utilizados em processos industriais em produção de enzima e metabólitos, por apresentar alta versatilidade metabólica (Souza, 2015). Além disso, são microrganismos presentes em todos os ambientes. Os bioprodutos produzidos por Talaromyces, em geral, podem estar localizados intra ou extracelulares. No caso de pigmentos naturais produzidos por fungos filamentosos é a maior parte extracelular, mas uma porção permanece na biomassa sendo necessária técnica de extração para obter o produto de interesse.

Os líquidos iônicos (LIs) podem ser usados como solventes alternativos para o processo de extração. Estes são conhecidos como solventes "verdes" que podem substituir solventes orgânicos tradicionais. Os LIs são sais compostos por íons grandes nos quais não formam rede cristalina bem definida podendo permanecer na forma líquida a temperatura ambiente ou temperaturas próximas a esta (Sousa et al, 2014). Estes compostos costumam resultar da combinação de cátions assimétricos constituído por um cátion orgânico e por um ânion orgânico ou inorgânico (Lima, 2014). Os LIs possuem propriedades físico-químicas muito interessantes como: viscosidade relativamente baixa, não são inflamáveis, apresentam estabilidades térmicas e eletroquímica maiores que solventes orgânicos clássicos, são facilmente recicláveis, sintetizados a partir de reagentes comerciais acessíveis e utilizando métodos sintéticos de relativa simplicidade (Sousa, et al. 2014). Diante do exposto, o objetivo deste trabalho foi avaliar a extração de colorantes naturais intracelulares de T. amestolkiae empregando LI como agente extrator associado com rompimento físico.

\section{MATERIAIS E MÉTODOS}

Os experimentos ocorreram em 3 etapas distintas. Primeiramente, em tubos Falcon, foram pesados $2 \mathrm{~g}$ de biomassa de Talaromyces amestolkiae e, posteriormente, adicionou-se 6 $\mathrm{mL}$ de LI $\left[\mathrm{C}_{4 \mathrm{mim}}\right] \mathrm{Cl}$. Os frascos foram submetidos à 5 ciclos de $5 \mathrm{~min}$ em sonicador e $1 \mathrm{~min}$ em banho de gelo. Em seguida, as amostras foram vertidas em frascos Erlenmeyers e permaneceram por 0,30 e $90 \mathrm{~min}$ em banho rotativo à $250 \mathrm{rpm}$ e $60^{\circ} \mathrm{C}$ para analisar a influência desta etapa na extração. Por fim, verteram-se as amostras em tubos Falcon, novamente. Fixou-se o tempo em banho.

Na segunda etapa, foi avaliada a influência da quantidade de ciclos em sonicador. Assim, ensaios de 10 ciclos em sonicador e banho de gelo foram realizados, nas mesmas condições do ensaio anterior e $30 \mathrm{~min}$ em banho rotativo. Na terceira etapa, foram realizados experimentos utilizando tubos graduados de vidro em homogeneizador durante $3 \mathrm{~h}$ à $32 \mathrm{rpm}$, nas proporções (1:3 m:v) de biomassa e LI.

Ao final de cada experimento, os tubos foram centrifugados à $6000 \mathrm{rpm}$ por 20 min à $25^{\circ} \mathrm{C}$. O sobrenadante foi empregado para determinação dos colorantes amarelos, laranjas e vermelhos através da leitura da absorbância em espectrofotômetro, à 400, 470 e $490 \mathrm{~nm}$, respectivamente. Os resultados foram expressos em termos de Unidades de Absorbância por 
volume $(\mathrm{UA} / \mathrm{mL})$, pois foi considerado o volume final obtido após a centrifugação em cada um dos ensaios. Todos os ensaios ocorreram em duplicata.

\section{RESULTADOS E DISCUSSÃO}

Na Figura 1 estão representados os resultados obtidos dos experimentos utilizando sonicador como equipamento de rompimento celular e variando o tempo de contato em banho rotativo.

Figura 1 - Resultados obtidos avaliando a influência do tempo em banho rotativo durante a extração com 5 ciclos de 5 min em sonicador e 1 min em banho de gelo.

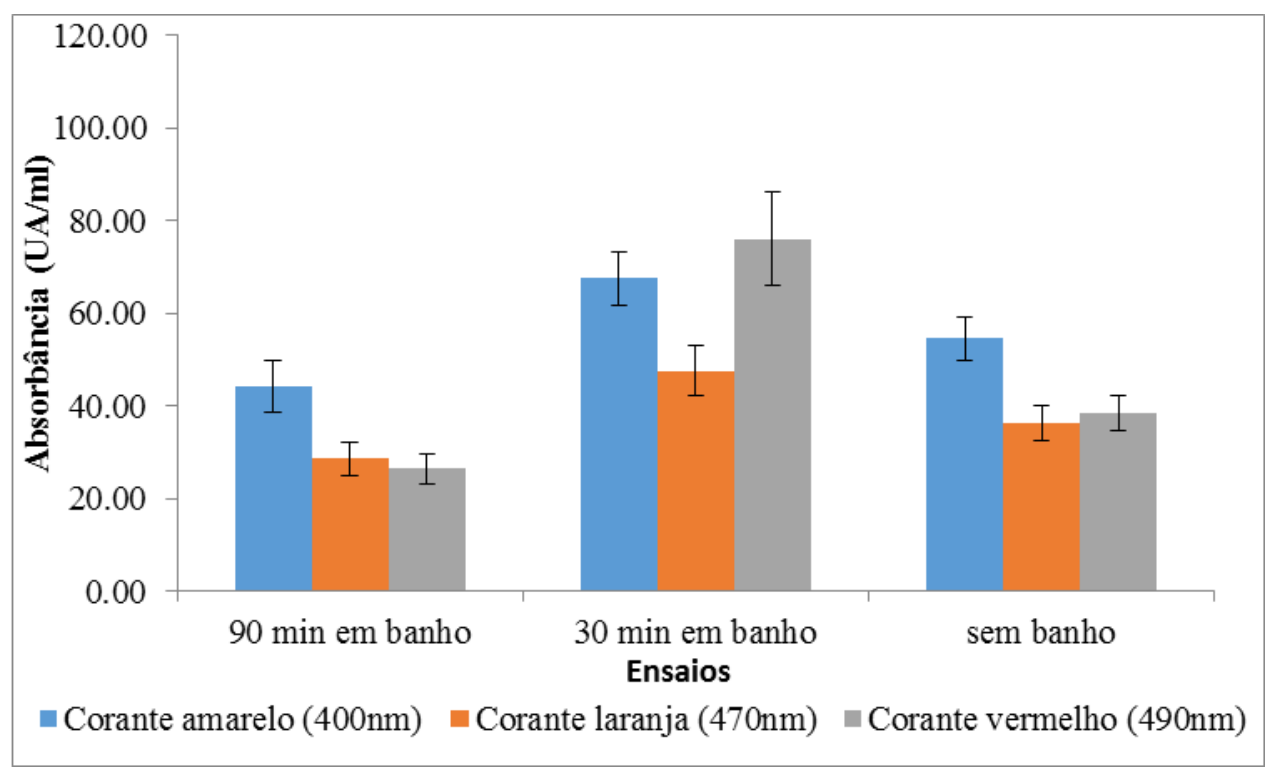

Como mostra a Figura 1, o tempo em banho rotativo influencia na eficiência da extração do corante. No ensaio em que as amostras foram submetidas a $30 \mathrm{~min}$ em banho, a concentração de corante vermelho - bioproduto de interesse - obtida foi, cerca de, 76 $\mathrm{UA}_{490 \mathrm{~nm}} / \mathrm{mL}, 48 \mathrm{UA}_{470 \mathrm{~nm}} / \mathrm{mL}$ e $67 \mathrm{UA}_{400 \mathrm{~nm}} / \mathrm{mL}$. Para o corante vermelho, este resultado apresentou concentração $98 \%$ maior que o resultado obtido na metodologia sem banho. A etapa do banho rotativo permite maior tempo e área de contato da biomassa e o LI, o que promove maior interação do agente extrator com a biomolécula de interesse.

Entretanto, nota-se que no ensaio em que as amostras permaneceram por $90 \mathrm{~min}$ em banho se atingiu concentração menor de corante. Pode ter ocorrido uma perda da cor pelo maior tempo de exposição a temperatura. Estudos de estabilidade da cor frente a temperatura estão sendo realizados a fim de comprovar essa hipótese. Além disso, o maior tempo de rotação dos frascos pode promover a formação de esferas da biomassa o que prejudica a interação do LI e a bioproduto. Sendo assim, fixou-se o tempo de $30 \mathrm{~min}$ para o próximo ensaio empregando sonicador e agitação em banho. 
A Figura 2 mostra os resultados obtidos em duas metodologias. Na primeira, foi utilizado apenas o homogeneizador para promover a interação do LI com a biomassa. Na segunda metodologia, utilizou-se 10 ciclos de $5 \mathrm{~min}$ em sonicador e $1 \mathrm{~min}$ em banho de gelo, em seguida, 30 min em banho rotativo.

Figura 2 - Resultados obtidos comparando metodologias distintas utilizando homogeneizador por $3 \mathrm{~h}$ e sonicador por 10 ciclos e $30 \mathrm{~min}$ em banho rotativo à $250 \mathrm{rpm}$ e $60^{\circ} \mathrm{C}$.

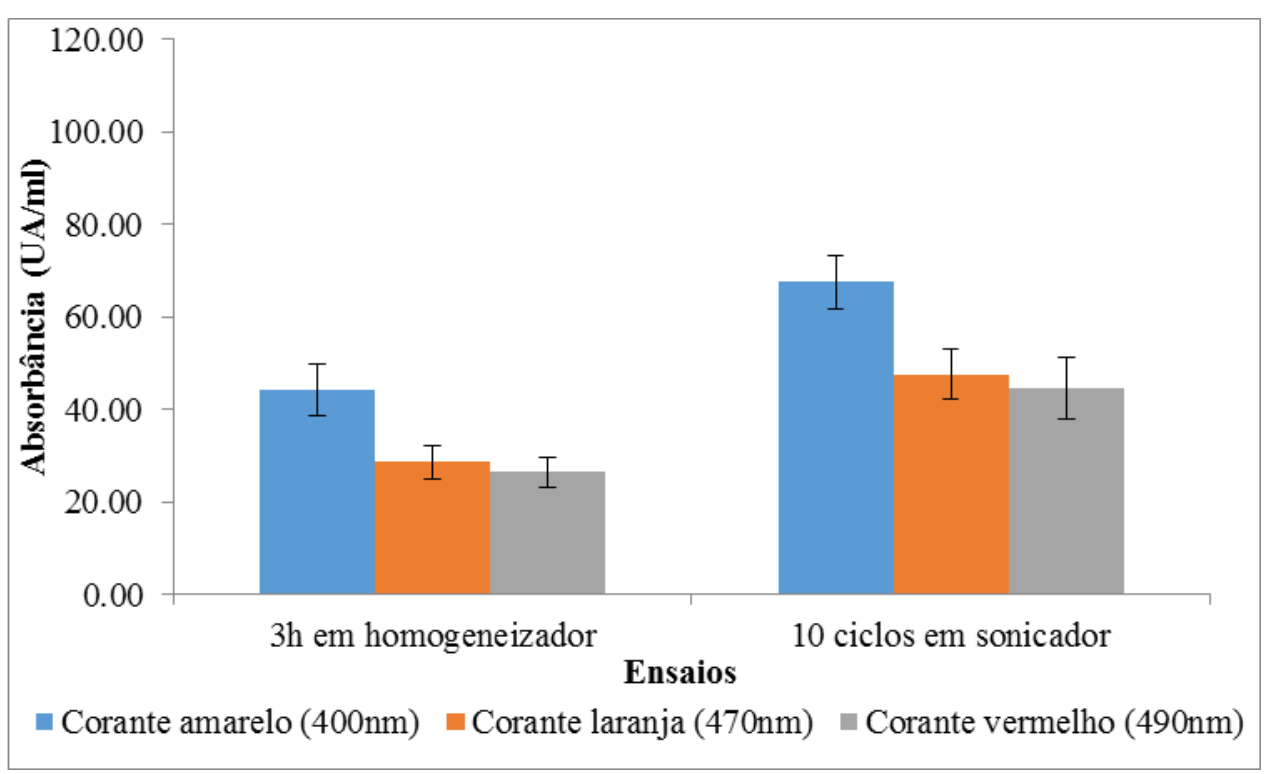

Foi possível averiguar que a extração se torna mais eficiente quando há auxilio de um agente rompedor. $\mathrm{O}$ sonicador promove a quebra das ligações presentes na parede celular da biomassa facilitando a interação do LI com o corante vermelho intracelular. Nos ensaios utilizando sonicador, a concentração máxima atingida foi, cerca de, $44 \mathrm{UA}_{490 \mathrm{~nm}} / \mathrm{mL}, 47$ $\mathrm{UA}_{470 \mathrm{~nm}} / \mathrm{mL}$ e $67 \mathrm{UA}_{400 \mathrm{~nm}} / \mathrm{mL}$. Para o corante vermelho, este resultado apresentou concentração $68 \%$ maior comparado à metodologia utilizando homogeneizador.

A partir da análise dos dois gráficos presentes nas Figuras 1 e 2, nota-se que o aumento de ciclos em sonicador não promoveu maior eficiência na extração. $\mathrm{O}$ ensaio realizado em 10 ciclos em sonicador atingiu concentração de corante vermelho de $44,54 \mathrm{UA} 490 \mathrm{~nm} / \mathrm{mL}$. O aumento do número de ciclos promove maior poder de quebra da biomassa o que pode aumentar a viscosidade do meio. A alta viscosidade pode prejudicar a interação do agente extrator com o corante presente no interior da célula. Sendo assim, fixou-se 5 ciclos em sonicador e $30 \mathrm{~min}$ em banho rotativo como metodologia padrão.

\section{CONCLUSÃO}

A partir dos dados obtidos, foi possível averiguar a melhor metodologia para extrair o corante vermelho intracelular. Sendo assim, averiguou-se que o sonicador, promove a quebra das ligações químicas da parede celular do fungo filamentoso e auxilia na interação do LI com 
o corante. Além de observar a influência do sonicador na extração, foi possível analisar a eficiência da extração variando o número de ciclos de sonicação e o tempo em banho rotativo. De acordo com os resultados atingidos, o aumento do número de ciclos não melhora a extração assim como maior tempo em banho de ultrassom também não auxilia a interação do agente extrator e a biomolécula de interesse. Sendo assim, foi possível fixar a metodologia com maior eficiência e economicamente mais viável, uma vez que altas concentrações de corante foram obtidas em menores quantidades de ciclos e tempos de experimento.

\section{REFERÊNCIAS}

LIMA, N. S. Degradação oxidativa de líquidos iônicos baseados em imidazólio utilizando processos fenton, foto-fenton e foto-feton solar. Dissertação (Pós-graduação em Engenharia de Processos) - Universidade Tiradentes, Aracaju, 2014.

SANTOS-EBINUMA, V. C. Produção e extração de colorantes naturais de Penicillium purpurogenum DPUA 1275. 2013. Tese (Doutorado em Tecnologia de Fermentações) Faculdade de Ciências Farmacêuticas, University of São Paulo, São Paulo, 2013.

SANTOS-EBINUMA, V. C., ROBERTO, I. C., TEIXEIRA, M. F. S., PESSOA, A. Improvement of submerged culture condition to produce colorants by Penicillium purpurogenum. Brazilian journal of Microbiology, v. 45, n. 2, p. 731-742, 2014.

SOUZA, P. M. Produção de protease por fungos filamentosos isolados do cerrado do centrooeste brasileiro. Tese (Pós-Graduação em Tecnologia Bioquímico-Farmacêutica) Faculdade de Ciências Farmacêuticas, Universidade de São Paulo, 2015.

SOUSA, R. C. S, TRINDADE P. S, TEIXEIRA, B. A. F, FLAUSINO O. L, NEVES M. T, BELATO C. R. Extração de corante têxtil em sistemas aquosos bifásicos baseados em líquidos iônicos. XX Congresso Brasileiro de Engenharia Química, Florianópolis, 2014.

TORRES, F.A.E.; ZACCARIM, B.R.; NOVAES, L.C.L.; JOZALA, A. F.; SANTOS, C.A.S.; TEIXEIRA, M.F.S.; SANTOS-EBINUMA, V.C. Natural colorants from filamentous fungi. Applied microbiology and biotechnology, p. 1-11, 2016. 